\section{A simple, inexpensive, constant-flow pump for delivering liquid reinforcers}

BERNARD T. ENGEL and REGINALD E. QUILTER, GERONTOLOGY RESEARCH CENTER, NATIONAL INSTITUTE OF CHILD HEALTH AND HUMAN DEVELOPMENT, Bethesda, Maryland, and THE BALTIMORE CITY HOSPITALS, Baltimore, Maryland 21224

A liquid reinforcer, controlled by a solenoid valve venting to atmospheric pressure, eliminates the chance of interrupted flow due to a clogged valve. The device maintains a constant flow at adjustable rates, and is inexpensive and easy to construct.

The purpose of this note is to describe a simple, inexpensive device that can be adapted readily to a wide range of psychological experiments in which controlled amounts of liquid reinforcers are needed.

Figure 1 is a schematic drawing of a prototype that we have used in most of our experiments. The salient features of this apparatus are: (1) Air enters the bottle at atmospheric pressure at a point well below the level of the reservoir; (2) the control valve is used to switch air, never the liquid. As we will show below, the first feature makes this device a constant-flow pump, while the second feature obviously minimizes maintenance. We emphasize that air must enter only through Port B, therefore all other fittings must be airtight.

In order to show that the device is a constant-flow pump, consider the case that liquid is leaving the system at Port $\mathbf{A}$, while outside air enters at Port B. The air obviously enters into the reservoir at Port C. Therefore, the pressure at Port $\mathrm{C}$ must be less than or equal to the pressure at Port $\mathrm{B}$, which is atmospheric pressure. Furthermore, this must be true irrespective of the height of the column of liquid above C.

While a formal proof of the pressure dynamics in this system has been omitted, it should be intuitively obvious that the flow past Port $A$ is a function of the viscosity of the liquid, the resistance of the system, and the distance from $C$ to $A$ as long as the liquid level is at or above $C$. Since viscosity and resistance will be constant for any given experiment, flow at $A$ becomes a function of the distance from $\mathrm{C}$ to $\mathrm{A}$.

We performed four tests to evaluate this system;

(1) We measured the volume delivered at
A during each of 12 successive 30-sec periods of flow; the height of the reservoir fell about $30 \mathrm{~cm}$ from the beginning to the end of this test. The volumes of the 1 st and 12 th samples were $16.1 \mathrm{ml}$. Two sample volumes were $16.0 \mathrm{ml}$; two sample volumes were $16.3 \mathrm{ml}$; one sample volume was $16.2 \mathrm{ml}$; and the other seven sample volumes were $16.1 \mathrm{ml}$.

(2) In order to test the linearity of the system, we measured the volume delivered at $A$ after periods of $1,2,3,4,5,10$, and $15 \mathrm{sec}$. The respective volumes were .7 , $1.3,1.7,2.3,2.9,5.5$, and $8.3 \mathrm{ml}$. A graph of these data and the origin would show almost no deviation from a straight line over the range of actual measurement, but $.1 \mathrm{ml}$ of deviation from linearity between the best-fit intercept and the origin.

(3) In order to test the accuracy of the system at very slow rates, we connected a solenoid valve to Port B, electronically opened the valve for $1 \mathrm{sec}$ every $4 \mathrm{sec}$, and counted the drops at $A$ during $121-\mathrm{sec}$ on periods and $123-\mathrm{sec}$ off periods. During each 1-sec on period, there were two drops, and within the next second there was one additional drop; the drop volume was about $.1 \mathrm{ml}$. At the end of this test, we turned the system off. It was apparent after $30 \mathrm{sec}$ that no additional drops were being formed.

(4) In order to test the system at high flows, we repeated Test 3 with the distance from $C$ to A greatly increased. This is done merely by adding a long tube at $\mathbf{A}$. At a flow rate of $23 \mathrm{ml} / 10 \mathrm{sec}$, there was an afterflow of $5.1 \mathrm{ml}$ over a period of $6.7 \mathrm{sec}$, with no further flow.

The dimensions of the pump are not critical; the primary consideration is the maximum volume of liquid needed. Our unit was constructed from Plexiglas tubing-1/2 in, $0 . d ., 1 / 8$-in. wall thickness, and $13 \frac{1}{2}$ in. long-and held an effective volume of about $250 \mathrm{ml}$. The air tube was also made from Plexiglas, $3 / 8$ in. o.d. 1/16-in. wall thickness. It was heated and bent into a right angle with arms of 13 in. and 1 in. A 3/8-in. hole was drilled into the side of the bottle, and the 1-in. arm was forced through this aperture so that about $1 / 4$ in. extended out. A 5/8-in. collar-1/2 in. o.d., 1/16-in. wall thickness-was ground to fit the curvature of the bottle and slipped over the air-tube extension and cemented into place. This collar added strength to the arm extension and insured the air seal between the extension and the bottle. An additional 1 -in. length of $3 / 8$-in. o.d. tubing was cemented inside the collar to attach the pressure hose from the control valve.

Two flat disks, $1 \frac{112}{2}$ in. diam, were cut from 1/8.in. sheet Plexiglas and were cemented to the top and bottom of the bottle after the top disk had been drilled and tapered to fit a Size 00 neoprene stopper. The unit was completed by threading a 6/32-thread, brass hose connector, buffered by an 0 -ring, into the side of the bottle $1 / 4 \mathrm{in}$. from the bottom.

We controlled the pump with a Model V5D25440, normally closed, solenoid valve that is operated by a $12 . \mathrm{V}$ dc coil (Skinner Electric Valve Division, New Britain, Connecticut). Flow rate was controlled by slipping a $1 / 4$-in. i.d., flexible plastic tube over the end of the brass hose connector and adjusting the height of the bottle to an appropriate level.

The system we have described above is easily maintained and highly reliable from day to day. We have used it for over 1 year in experiments with fruit juice reinforcers, and we have had no maintenance problems. Furthermore, the initial cost of construction is negligible. The linearity and reliability should make this apparatus very useful in a number of psychological studies.

The major shortcoming of this system is that it has a high degree of afterflow; however, the effect at low flows seems insignificant. Since most psychological research is done under conditions of low volume, we believe this apparatus will prove quite useful.

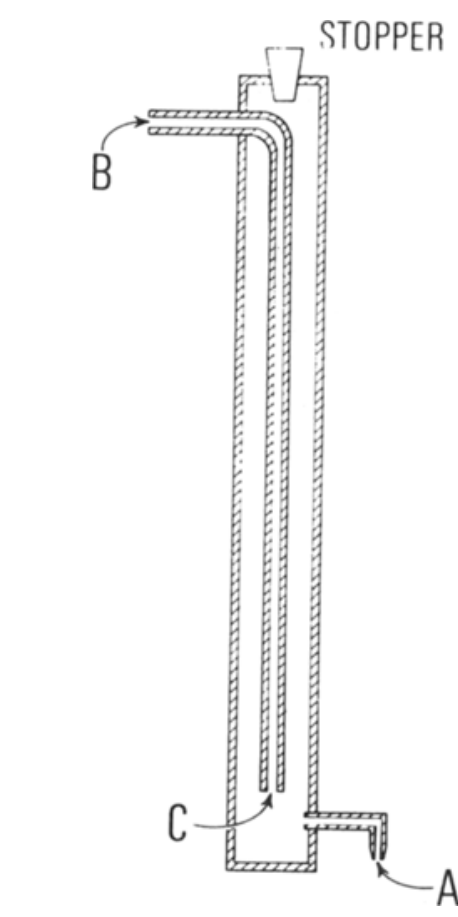

Fig. 1. Schematic drawing of constant-flow pump. 